\title{
NARRATIVIDADE, MEMÓRIA E DESCOLONIZAÇÃO NO ROMANCE O RETORNO, DE DULCE MARIA CARDOSO
}

\author{
NARRATIVITY, MEMORY AND \\ DECOLONIZATION IN THE NOVEL \\ THE RETURN, BY DULCE MARIA CARDOSO
}

Claudia Amorim ${ }^{1}$

Suzana Costa da Silva ${ }^{2}$

\section{RESUMO}

O artigo faz uma análise de O retorno, de Dulce Maria Cardoso, ressaltando sua linearidade memorialística; além de discutir a relevância da memória no processo de descolonização e no deslocamento dos chamados retornados a Portugal, sob a ótica do personagem-narrador do romance, o jovem Rui. A memória, diante de toda a fragmentação do indivíduo, proporciona para a literatura também um discurso fragmentado de histórias, antes conhecidas através das vozes dos vencedores, presente no discurso hegemônico. Recuperam-se aqui as histórias de um passado cheio de lacunas, que na contemporaneidade são munidas de trauma e verdade. A construção da narrativa O retorno, de Dulce Maria Cardoso, alicerça-se sobre a base da memória, desde aquela que pertence unicamente à autora, retirada de seu convívio em Angola aos treze anos de idade, até a visão de Rui, igualmente retornado a uma pátria desconhecida. O romance é contado sob a base mnemônica, e revela a capacidade de os sujeitos viverem os acontecimentos e contá-los ao mesmo tempo ou décadas depois, introduzindo no romance contemporâneo português as particularidades de uma pós-memória.

PALAVRAS-CHAVE: Memória. Retornados. Descolonização. Dulce Maria Cardoso. 


\section{ABSTRACT}

The paper is an analysis of The return, by Dulce Maria Cardoso, which emphasizes its memory linearity, besides discussing the relevance of memory in the process of decolonization and displacement of the so-called "returned" to Portugal, by the perspective of the character/narrator, the young Rui. The memory, in the face of all the fragmentation of the individual, also provides for literature a fragmented discourse of stories, previously known through the voices of the winners, present in the hegemonic discourse. Here are recovered the stories of a past full of gaps, which in contemporaneity are equipped with trauma and truth. The construction of the narrative of The return, by Dulce Maria Cardoso, is based on memory, from that which belongs solely to the author, withdrawn from her coexistence in Angola at the age of thirteen, until the vision of Rui, who has also returned to an unknown homeland. The novel is told on a mnemonic basis and reveals the subjects' ability to live events and tell them at the same time or decades later, introducing to the contemporary Portuguese novel the particularities of a post-memory.

KEYWORDS:Memory. Returned. Decolonization. Dulce Maria Cardoso.

O retorno, de Dulce Maria Cardoso, que teve em 2012 seu lançamento no Brasil, é obra vencedora do Prêmio Especial da Crítica Literária e condecorada como Livro do Ano dos jornais Público e Expresso em Portugal. De uma sutileza comovente, o romance aborda questões ainda pouco reveladas por portugueses que tiveram suas vidas desfeitas pelos efeitos da descolonização tardia em Angola, sendo obrigados a migrar para Portugal. No regresso à pátria-mãe, esses sujeitos não puderam se sentir acolhidos; assunto que permaneceu por décadas reservado somente ao âmbito familiar dos retornados quando esse possibilitava a rememoração.

Cardoso, hoje com 57 anos de idade, carrega consigo marcas da sua experiência com a realidade angolana e portuguesa da década de 1970. A autora vivenciou com sua família o conflito local na ex-colônia, a saída repentina e a chegada problemática a Portugal, assim como a emblemática família retornada de sua ficção. Em diferentes entrevistas, Dulce Maria Cardoso faz questão de configurar sua obra como ficcional, o que a afasta de uma pessoalidade quase indissociável. Ao jornalista português Mario Crespo no Jornal das 9 do canal português SIC Notícias, observa: "vivi os acontecimentos. O livro é quase completamente ficcional, esta família não é a minha. Eu não sou o rapaz, isto é, eu não escolhi não só o rapaz para tornar claro que não sou eu, teve outras razões. Eu vivi parte dos acontecimentos" (CARDOSO, 2012a, on-line).

A lembrança desse processo de descolonização na obra de Cardoso apresenta-se por uso de uma escrita linear, objetiva, mas que demonstra toda a complexidade vivida por portugueses e seus descendentes quando da 
chegada a uma terra, para eles desconhecida. Ainda que tenha vivenciado o conflito civil em Angola, com as memórias de uma guerra e os relatos das mortes e fugas, não sentiu, talvez por ser muito jovem, os impactos e horrores de maneira tão consciente como seus pais e vizinhos, e a escritora revela a ingenuidade de seus olhos de criança, mesmo nos momentos mais críticos da guerra civil:

era lindo ver as balas luminosas, da sede do MPLA para a FNLA. [...] O recolher obrigatório fazia com que não se voltasse a horas para casa. As festas prolongavam-se pela noite. Fazia com que os professores faltassem às aulas. Fazia com que tudo fosse extremado, urgente. Muitas coisas deixaram de ter importância. [...] E até, se tivermos talento para isso, habituamo-nos a ser felizes nestes contextos (CARDOSO, 2015, on-line).

O retorno, embora não seja autobiográfico (segundo afirmação da própria autora), mostra uma proximidade muito grande com sua vida, quando serão discutidos preconceitos e intolerância com os que chegam das colônias, a falta de subsídio do governo, a exclusão social, entre outros aspectos que Dulce Maria Cardoso narrará com propriedade memorativa e imaginativa, dando corpo ao estigma de ser um "retornado" na sociedade portuguesa do pós- 25 de Abril.

E esse drama será narrado na obra por Rui, um adolescente de 15 $\operatorname{anos}^{3}$ que teve sua vida em Angola marcada pela guerra nas colônias que nesse país durou 13 anos (1961-1974), como também pela guerra civil, deflagrada após a independência. Apesar dos conflitos bélicos, o jovem e sua família vivem e estabelecem com esse país uma relação íntima. Habituados à vida local, à cultura, às pessoas, relacionam-se muito bem entre si e com os outros colonos, até o momento em que os conflitos bélicos começam a alcançar-lhes o quintal.

Obrigados a deixar tudo para trás, a fim de salvarem-se, a família de Rui, como tantas outras, depara-se com a realidade de expatriados. A imaginária metrópole, presente apenas nos livros de História e Geografia do Liceu, é, para a maioria dos jovens nascidos na África e filhos de colonos portugueses, um lugar distante com estatuto de Império.

Ana Filipa Prata (2014), citando Isabel F. Gould, destaca que os anos 1990 são aqueles em que emerge uma literatura de retornados, ex-colonos oriundos dos territórios africanos, que acentua o tom memorialístico da natureza dessas narrativas. Muitas delas partem da experiência familiar, não dos retornados em si, mas de seus descendentes, geralmente filhos de portugueses nascidos na África e que nunca haviam saído das colônias. O drama desse retorno é então problematizado ainda pelo fato de as memórias da Metrópole, e do país para o qual regressam os ex-colonos, serem então referidas pelos seus descendentes que, a rigor, não poderiam ser chamados de retornados. 
Em O retorno, de Cardoso, a narrativa remonta ao ano de 1975, tempo extremamente dificultoso para os moradores portugueses das ex-colônias em África, marcado por conflitos civis, medo da violência e prisões repentinas, retaliações dos povos africanos, etc. Todos esses acontecimentos culminariam na imperiosa necessidade de deixar o país, algumas vezes partindo para a África do Sul, mas quase sempre regressando a Portugal, a fim de se escapar da violência das guerrilhas locais. A saída não foi voluntária, tampouco despreocupada. Como observam os estudiosos, nesse período conturbado da história, ocorrido entre os anos de 1974 a 1976, viveu-se a mais significativa (e traumática) ponte aérea feita de Luanda a Lisboa de todos os tempos. Segundo Margarida Calafate Ribeiro (2020, p. 9) "É neste mar de silêncio que a guerra e o 'retorno' atingem a geração seguinte, aquela que era criança aquando da mobilização do pai ou que ainda nem era nascida, a geração dos 'filhos da guerra', dos 'filhos dos retornados', dos afro-descendentes."

Os fatos, na obra de Cardoso, são relatados por meio de um narrador-personagem, um "filho da guerra", como propôs Ribeiro, que deixa transparecer inconscientemente, durante grande parte da narrativa, o discurso do colonizador, especialmente no que tange à vida em Angola, marcada pelo bom relacionamento com os demais colonos e por uma naturalização de um sentimento de superioridade, de domínio e de poder. Em muitos momentos da narrativa, Rui, ainda uma criança, demonstra estar afinado com a visão de mundo colonialista e racista de seus pais e da maior parte dos colonos portugueses, o que torna o relato cada vez mais próximo da realidade estabelecida no contexto da guerra pela independência e da guerra civil, sendo o jovem incapaz de se dar conta dos privilégios garantidos por sua condição e por sua cor. Esse viés colonialista parecia aos colonos naturalizado, sustentando-se na própria organização da sociedade. Conforme observa o historiador brasileiro Waldir Freitas Oliveira em seu artigo Brancos e pretos em Angola:

não há, pois, como negar-se que o elemento negro em Angola vive terrivelmente inferiorizado em relação ao branco. Êste constitui a classe privilegiada, possui a riqueza e o comando da vida econômica, política e administrativa da colônia. É terrivelmente chocante, por exemplo, compararmos os bairros residenciais dos brancos com os habitados pelos nativos em qualquer das suas grandes cidades. Habitam os primeiros em majestosas residências, construídas dentro dos mais modernos moldes arquitetônicos, em ruas asfaltadas e amplamente iluminadas. Habitam os negros em miseráveis choupanas de paredes de terra e cobertas de palha, onde não existe luz nem água encanada, em ruas sem calçamento e sem iluminação (OLIVEIRA, 1965, p. 35).

Crítico e impulsivo, à medida que o tempo passa e já na metrópole, a voz do jovem Rui se modifica, relativizando os lugares estanques do dominador e do dominado, pela experiência vivida entre a angústia e o desespero. Em um romance de configuração moderna e linear, a narrativa apresenta as 
marcas do tempo e as experiências vividas tanto no espaço colonial quanto no espaço marginalizado da metrópole, como um roteiro preestabelecido a ser desatado ao longo da obra.

A era moderna, de que o romance de Dulce Maria Cardoso se aproxima por suas peculiaridades, é a do sujeito cartesiano, herança do Iluminismo, em que o cogito, ergo sum ${ }^{4}$ se apresenta como um reflexo de um tempo movido pela razão e pelo predomínio da centralidade humana. A racionalização dos elementos da vida se transfigura na narrativa pela fala linear do narrador, que, em uníssono, oferece ao leitor a visão e a relação que estabelece com o mundo, aproximando-se da perspectiva do romance mais tradicional.

Segundo Walter Benjamin, em O narrador, a "origem do romance é o indivíduo isolado, que não pode mais falar exemplarmente sobre suas preocupações mais importantes e que não recebe conselhos nem sabe dá-los" (BENJAMIN, 1994, p.19). Tal como o protagonista d'O retorno, que narra o regresso a partir de sua experiência e de sua visão de mundo, o leitor vai lendo os acontecimentos pela ótica dessa experiência personalizada e cartesiana, porque racionalizada. No entanto, na narrativa de Rui, não faltam alusões a outros pontos de vista, contrários à visão colonialista, que ele reproduz pelo viés da memória. Nesse sentido, o romance mostra sua natureza plurivocal, ao mesmo tempo em que revela a complexidade desse tempo.

$\mathrm{Na}$ Modernidade os caminhos são previsíveis, as rotas claras e o objetivo da diegese é atingido com facilidade, contudo a narrativa que se serve da memória para sustentar o narrado produz inflexões, subjetividades, contradições nada desprezíveis. Marcas do passado, da vida e da memória dos retornados surgem como flashbacks, e ainda assim, a narrativa segue seu curso normalmente, definida por seu tempo/espaço. Objetiva, a história obedece a uma lógica temporal. À medida que o protagonista Rui vai narrando os fatos numa linearidade temporal, a narrativa se faz acontecer, imbuída sempre de uma carga sentimental do adolescente pela vivência na terra em que nasceu (Angola), enquanto vive os percalços de uma metrópole a que não pertence (Portugal).

O uso de elementos textuais que escondem e camuflam vocábulos que não podem ser ditos é mais uma estratégia do narrador para poupar-se do peso e do incômodo que cada palavra traz a seu imaginário. Rui diz "cá" ou "lá" quando se refere ao espaço, quando na verdade não falar "Angola" ou "Portugal" é simplesmente deixar o vazio e o silêncio tomar conta de seus pensamentos e da sua narrativa. "Os de cá não têm razão quando dizem que os pretos não gostavam de nós, os pretos gostavam de nós e queriam que ficássemos lá, foram os de cá que os mandaram expulsar-nos de lá. Por que haviam de fazer uma coisa dessas. Por inveja, os de cá são muito invejosos" (CARDOSO, 2012b, p.232). 
A metrópole do imaginário de Rui é mais interessante do que o local a que chega com a mãe e a irmã, além de tornar intangíveis as moças bonitas da metrópole; aquelas que outrora regiam os seus sonhos. Em outro momento, ainda sem conhecer Portugal, país até então acessível apenas pelas aulas do Liceu, tinha afirmado: "Mas, na metrópole há raparigas lindas. Raparigas com brincos de cerejas, laços de cetim no cabelo e saias rodadas pelo joelho como nas fotografias das revistas que comprava na tabacaria do Sr. Manuel" (CARDOSO, 2012b, p.28). Percebe-se que, além de toda idealização, há na fala de Rui um certo desconforto revelado pelo uso da adversativa "Mas", o que parece sublinhar sua desconfiança com relação às qualidades presumidas de Portugal. O "Mas" surge mais de uma vez na narrativa do menino, como uma justificativa antecipada à frustração resultante de tanta idealização. Porém, essa idealização não dura mais que dois capítulos. $\mathrm{Na}$ chegada à terra do desejo (e da necessidade), Rui sofre seu primeiro desmantelamento: "então a metrópole afinal é isto" (CARDOSO, 2012b, p. 65).

O pronome "isto" também é empregado como estratégia narrativa, emitindo um resumo de tudo o que poderia ter sido dito e não foi, dando conta de ser tudo e nada ao mesmo tempo. Rui está nitidamente frustrado quando adentra em uma terra nem um pouco parecida com o que imaginou. Seu desencanto perpassará toda a narrativa desde a sua chegada a Lisboa, e irá se amalgamar a seu relato distanciado; o relato de alguém que ocupa um lugar marginalizado no país que vive ainda a euforia da Revolução de Abril.

A representação dos excluídos na obra configura-se nessa narrativa pelo lugar que Rui e sua família (metonímia de tantos outros retornados) ocupam no novo espaço. Talvez o fato de ser um jovem a narrar as desmazelas não só das estruturas ainda coloniais na Angola pós-independente, como o imaginário colonial em um país pós-revolucionário, acabe por nos colocar diante de um certo fracasso das utopias, quando ainda nelas se acreditava. Só os olhos de um jovem poderiam apontar para as contradições do momento, evidenciando os descaminhos na construção do novo. Contudo, também é fato de que aos infantes não cabe a palavra. Essa infância (ou infante) sem voz, a priori não representa valor na sociedade. Nesse sentido o professor João Cezar de Castro Rocha em seu artigo intitulado A guerra de relatos no Brasil contemporâneo. Ou: a "dialética da marginalidade" atenta para a questão de que "em latim infante é o 'in-fans', ou seja, aquele que não fala, não se expressa, necessitando auxílio paternal” (ROCHA, 2006, p. 49). E, na obra de Cardoso, a única voz que se expressa de maneira contínua é a de um menino, ainda que seja um discurso testemunhal e solitário. Ocupando esse lugar de narrar, pelo viés da marginalidade, a estratégia narrativa se coaduna com o que Rocha chama de a dialética da marginalidade que, segundo ele,

pressupõe uma nova forma de relacionamento entre as classes sociais. Não se trata mais de conciliar diferenças, mas de evidenciá-las, recusando-se a improvável promessa de meio-termo entre o pequeno círculo dos donos do poder e o crescente universo dos excluídos. Nesse contexto, vale repetir para 
evitar mal-entendidos, o termo marginal não possui conotação unicamente pejorativa, representando também o contingente da população que se encontra à margem, no tocante aos direitos mais elementares, sem dispor de uma perspectiva clara de absorção, ao contrário do malandro (ROCHA, 2006, p.56).

Esse conceito se baseia na possibilidade real de produções de indivíduos até então excluídos e marginalizados pela sociedade, que logram produzir uma escrita, tornando público o discurso submerso de sujeitos anônimos. Para Rocha, a dialética da marginalidade leva o sujeito, pela primeira vez, a entender o processo de exclusão social ao qual ele pertence.

Rui é, portanto, a expressão da marginalidade, não só por ser um retornado no contexto da descolonização, como também pelo fato de ser um jovem, a quem não se costuma ouvir. No lugar de dupla marginalidade, o narrador se esforça por ordenar seu relato de um mundo inteligível. Dispõe os acontecimentos da memória com aspectos cotidianos e reais e é a partir desse discurso linear, embora memorialístico, que o jovem passa por um processo involuntário e doloroso de amadurecimento pessoal.

Para ordenar seu fluxo de consciência, surge o mecanismo da rememoração, como fio da experimentação de tempos distintos e associação de ideias, a partir de lembranças de um tempo passado, um passado recente e familiar que perde rapidamente espaço ao inexorável presente. O seu longo relato, como um monólogo interior, apresenta-se por meio do discurso indireto e indireto-livre, em que a opinião do rapaz e as falas daqueles com quem conviveu ou convive são relatadas por ele ou inseridas no discurso, através de suas memórias. Um exemplo dessa memória que ele resgata, sendo a de outrem, pode ser observada quando a narrativa dá conta de um tempo anterior ao do seu nascimento, quando da chegada da mãe, D. Glória, a Luanda, para casar-se com Mário, então seu noivo:

a mãe de costas para o mar, sem reconhecer o pai, sem conhecer a terra que tinha em frente, os guindastes pareceram-me mais altos do que as nuvens, o porto tão grande, cabiam ali cem cabeços de macieiras. A mãe teve medo dos pássaros que gritavam como os de Lisboa, o vosso pai disse-me que se chamavam gaivotas. Dos pretos não tive medo, não tinham nada de especial, eram só pretos. O porto tinha um cheiro ácido, como se o mar tivesse azedado, o porto em Lisboa não cheirava mal (CARDOSO, 2012b, p. 25).

O trecho é iniciado pela narração de Rui e sua lembrança sobre o que lhe foi contado sobre esse acontecimento e, no momento seguinte, a fala de sua mãe introduz-se na narrativa e assume o lugar de enunciação.

Em determinado momento da narrativa, o jovem Rui aparece refletindo sobre a vida em um quarto de hotel "na Linha", ou seja, um hotel cinco estrelas e à beira-mar, mas sem regalias ou privilégios próprios dos turistas, uma vez que o hotel havia sido destinado a abrigar os retornados. Sem lugar, nesse ambiente neutro de hotel, Rui divaga: "um quarto pode ser 
uma casa e este quarto e esta varanda de onde se vê o mar é a nossa casa" (CARDOSO, 2012b, p.163). Além da memória como um fio que busca articular dois mundos distintos, a sua narração parece buscar um sentido para toda a sua vivência, sendo fundadora inclusive de um novo lugar/tempo quando, ao repetir por cinco vezes que o quarto de hotel pode ser sua casa, parece desejar com isso instaurar alguma solidez ao espaço transitório do quarto de hotel que divide com a irmã e a mãe, enquanto espera (sem saber se o deve fazer) a chegada do pai, retido em Angola pelas tropas em guerra, na ocasião da partida.

Na obra de Cardoso, há dois momentos que marcam e caracterizam o estilo de narrativa que o menino Rui desenvolverá: a vida antes e depois da chegada na metrópole. No que concerne ao antes, vê-se a descrição da capital angolana, feita sempre por um olhar amoroso e pueril em relação à sua terra, à casa da família, aos vizinhos e amigos em Angola. Nesse momento, Rui ainda é capaz de falar vividamente das ruas, das festas, dos vizinhos e do quintal de maneira minuciosa e terna. É, de fato, o único local que conhece e, portanto, entende perfeitamente o que é pertencer a uma pátria, e Angola é a sua pátria-mãe. A necessidade da partida da sua terra natal o faz se sentir desiludido e instaura-lhe um sentimento de luto de uma Angola que ele sabia que perderia, ao mesmo tempo em que também se mostra desconfiado com o que está por vir, já que não via outro futuro a não ser na colônia. No dia da partida, parece prenunciar uma mudança definitiva:

a nossa última manhã. Tão silenciosa apesar dos tiros. Nem tiros conseguem desfazer o silêncio da nossa partida, amanhã já não estamos aqui. Ainda que gostemos de nos enganar dizendo que voltamos em breve, sabemos que nunca mais estaremos aqui, Angola acabou. A nossa Angola acabou (CARDOSO, 2012b, p.14).

A nostalgia que sente é o reflexo de uma identidade fragilizada, pois, deslocado, passa a sofrer com o não pertencimento. Logo, todo seu processo identitário é colocado em questão, por não pertencer mais a lugar nenhum. Ainda em seu país, com a partida iminente começa a imaginar a metrópole como um local em que seria possível viver, sendo essa a terra familiar a seus pais, onde, afinal, nasceram e cresceram. Mas a verdadeira e decepcionante percepção sobre Portugal ocorre, de fato, quando adentra a distante capital portuguesa, que, além disso, os rotulava de "retornados". 6

Com o passar dos meses na metrópole decepcionante, constrói um novo lugar ideal em seus pensamentos: a América. Lá, sim, seria feliz com sua família, e esse deveria ser o destino de todos logo após a chegada do pai, ideia à qual se apoia nos primeiros momentos em Lisboa. Rui percebe que é preciso deixar para trás a Angola da sua memória, ainda que se refugie em recordá-la, e abandona os sonhos de viver na metrópole, criando novas expectativas. Pensar na América é a utopia necessária para continuar vivo, enquanto segue vivendo a distopia da realidade dos "retornados": 
a única coisa que me interessa saber é como vou levar minha mãe e irmã para a América, e para ir para América tanto faz um ano de escola a mais ou a menos. Tenho é de continuar a decorar as palavras do dicionário, decorar palavras é mais difícil do que pensava, há muitas de que nem conheço o significado em português (CARDOSO, 2012b, p.192).

O processo de comunicabilidade de Rui com aqueles com quem tem de interagir, durante sua estadia no hotel em Lisboa, ocorre concomitante ao seu crescimento como pessoa. De um garoto sem responsabilidades reais, passa a ser o chefe da família em Portugal. É visível a constante alteração na fala desse protagonista, imbuído de vontades e desejos que a própria idade e maturidade justificam quando se faz necessário tomar decisões. Em África, Rui é um menino de 15 anos que se diverte com os amigos, frequenta o Liceu, interessa-se por meninas da mesma idade e possui uma vida privilegiada como tantos outros portugueses e descendentes nas colônias. Suas peripécias de garoto são contadas na obra apenas pelo recurso da memória, pois, quando a narrativa se inicia, Rui e sua família estão prestes a deixar o solo africano. Com o passar do tempo, a nova e difícil vida em Portugal impõe-lhe o crescimento.

Essa voz que dialoga no romance vai ganhando autonomia à medida que os fatos se sucedem e os sentimentos se alternam entre comoção, tristeza, desamparo, ódio e, por fim, ressentimento. Sem estabelecer laços no novo espaço, Rui cria seus próprios cenários e se esgueira por espaços aos 'hóspedes' não destinados, como o terraço do hotel, lugar de onde pode mirar a cidade por outros ângulos. Escreve longas cartas para ninguém, marcando sua necessidade de narrar e criando a sua versão dos fatos. Esse narrador-personagem vai ao longo do seu discurso mostrando sua gradual maturidade e sua absoluta condição indefesa por se encontrar, como quase todos os retornados, deslocado e perdido nesse tempo/espaço que não the pertence, um tempo/espaço, que não inclui os retornados da África, mesmo marcado pela abertura político-social que foi o pós- 25 de Abril. Somente a partir da observação crítica do seu entorno visível em seu discurso, é que se pode perceber o grau de confusão em que o jovem se encontra diante de outra realidade e cultura, ao mesmo tempo em que problematiza e observa, com isenção de estrangeiro, essa pátria desconhecida.

Preso por todas as amarras a esse tempo de mal-estar que oprime os indivíduos, Rui, como todos os seus conterrâneos, vive sob o controle das autoridades locais. Em Lisboa, confinado num hotel de luxo, com outras famílias de retornados expatriados das ex-colônias, vê suprimidos todos os serviços próprios de um hóspede. A piscina é esvaziada, a comida é de pouca qualidade e as roupas oferecidas são inapropriadas aos seus tamanhos. "São tempos conturbados" (CARDOSO, 2012b, p.71), diz, incessantemente, a diretora do hotel, a fim de justificar a retirada de benefícios aos recém-chegados. Diante de tamanha desilusão, o protagonista não disfarça seu desencanto cada vez que conhece mais a terra de seus pais. 
Rui é o indivíduo mais próximo ao leitor, e, portanto, é aquele que traz as marcas e memórias mais profundas desse tempo. Em Lisboa, segue preocupado, enquanto espera sem muita certeza a chegada do pai, preso em terras africanas pelos independentistas. Vive o profundo mal-estar e se perde em seus próprios devaneios, anseios e angústias, sentimentos que procura disfarçar, em razão da responsabilidade para com a família e o sentimento de culpa que carrega pela prisão do pai. É um jovem amadurecido a repetir: "tenho de ser capaz de tornar a pensar e a sentir uma coisa de cada vez" (CARDOSO, 2012b, p.173). Quando o fardo carregado era a sobrevivência, havia de se pensar um dia após o outro.

No romance, a narrativa de um possível retorno do pai também permeia o romance e se soma ao relato do retorno à terra portuguesa. Nesse sentido, o título do romance oferece essa ambiguidade, ao relacionar-se aos retornados como um todo, mas também à possibilidade de retorno do pai perdido em Angola. Como "retornados", muitas são as dificuldades enfrentadas por Rui e seu conterrâneos; o frio, o medo e a insegurança da possibilidade de futuro em Portugal são compartilhados pelos desalojados do Ultramar. Ao menino, sem pátria, bastava a tão esperada chegada do pai acontecer, para que todos os seus medos e pesadelos desaparecessem. Diante de tantos traumas desde a saída de Angola, o que permanece visível na narrativa é a mudança e amadurecimento de Rui, que busca não perder a esperança.

Se calhar sou eu que vejo mudança onde na verdade não há mudança nenhuma, se calhar sou eu que invento mistério onde não há mistério nenhum, se calhar a mudança não existe e vamo-nos só mostrando de maneiras diferentes. Eu não sinto que mudei mas tenho a certeza que se a mãe que usava o pó azul nos olhos me visse agora aqui ia dizer, não pareces tu. E não havia de ser só por causa de a barba ter crescido (CARDOSO, 2012b, p.262).

A partir do momento em que efetivamente o pai retorna, o jovem percebe o quanto precisou mudar e crescer para alcançar o patamar de chefe de família e se permite voltar a sonhar e a reconhecer sua condição de filho: "o pai está aqui e já não sou o chefe da família” (CARDOSO, 2012b, p.222). O retorno do pai, afinal, parece ser a garantia de pertencimento possível aos olhos do jovem Rui. Pai-pátria. Quando nem Angola, nem Portugal são espaços de pertencimento, a chegada inesperada do pai, que já parecia perdido aos olhos do filho, recompõe o chão-pátria de Rui, ainda que esse chão só tenha a solidez dos afetos familiares.

\section{REFERÊNCIAS}

BENJAMIN, Walter. O narrador: considerações sobre a obra de Nikolai Leskov. In: BENJAMIN, Walter. Obras escolhidas. São Paulo: Brasiliense, 1994. v. 1. 
CARDOSO, Dulce Maria. Dulce Maria Cardoso fala sobre O Retorno com Mario Crespo. SIC TV, [S. 1.], 29 mar. 2012a. Entrevista concedida a Mario Crespo. Disponível em: https://www.youtube.com/watch?v=ytQs66q6GQU. Acesso em: 25 nov. 2019.

CARDOSO, Dulce Maria. Há retornados que acham que sou uma traidora. Jornal Público. Coluna Ípsilon [S. l.], 17 set. 2015. Entrevista concedida a Kathleen Gomes. Disponível em: https://www.publico.pt/2015/09/17/culturaipsilon/noticia/dulce-1708071. Acesso em: 25 jan. 2020.

CARDOSO, Dulce Maria. O retorno. 1.ed. Rio de Janeiro: Tinta-da-china Brasil, 2012b.

DESCARTES, René. Discurso do método. In: Descartes. Vida e obra. Tradução: Enrico Corvisieri. São Paulo: Editora Nova Cultural Ltda. (Coleção: Os pensadores).

LIRA, Rosário. Descolonização Portuguesa: Os 500 Dias do Fim do Império. RTP- Rádio e Televisão de Portugal.2018. On-line. Disponível em:https:// media.rtp.pt/descolonizacaoportuguesa/introducao/descolonizacao-portuguesa/. Acesso em: 15 out. 2020.

OLIVEIRA, Waldir Freitas. Brancos e pretos em Angola. Afro-Ásia, Salvador, n. 1, p. 33-39, 1965. Disponível em: https://rigs.ufba.br/index.php/afroasia/ article/view/20230/0. Acesso em: 12 mar. 2018.

PRATA, Ana Filipa. O cronótopo do hotel e a formação da memória em $O$ retorno, de Dulce Maria Cardoso. In: Navegações. V 7, n. 1, p. 69-76, jan-jun 2014.

RIBEIRO, Margarida Calafate. Arte E Pós-Memória - Fragmentos, Fantasmas, Fantasias. Diacrítica - Revista do centro de estudos humanísticos. Vol. 34, n. ${ }^{\circ}$ 2, 2020, pp. 4-20. Disponível em: https:// https://estudogeral.uc.pt/ bitstream/10316/90496/1/Arte\%20e\%20Pos\%20Memoria.pdf

ROCHA, João Cezar de Castro. A guerra de relatos no Brasil contemporâneo. Ou 'A dialética da marginalidade'. Revista Letras (UFSM), n. 32, p. 23-70, jun. 2006. Disponível em: https://periodicos.ufsm.br/letras/article/view/11909. Acesso em: 11 out. 2015.

Recebido para avaliação em 31/05/2021 Aprovado para publicação em 04/08/2021

\section{NOTAS}

1 Professora Associada de Literatura Portuguesa da UERJ, com atuação na Graduação e no Programa de Pós-Graduação em Letras. Coordenadora do Programa de Estudos Galegos (em Convênio com a Xunta de Galicia). Link para o Lattes: http://lattes.cnpq. br/9132179645460003 
2 Mestra e Doutora em Literatura Portuguesa pela Universidade do Estado do Rio de Janeiro (UERJ). Professora de Língua Portuguesa e Literaturas da rede Estadual - RJ (SEEDUC), e da educação básica na FUNDEC - Fundação de Apoio à Escola Técnica, Ciência, Tecnologia, Esporte, Lazer, Cultura e Políticas Sociais de Duque de Caxias. Link para o Lattes: http:// lattes.cnpq.br/2966619625510767

3 Embora a obra não apresente claramente a idade do jovem, Dulce Maria Cardoso confirma essa informação em diversas entrevistas concedidas.

4 Penso, logo existo, expressão empregada pelo filósofo francês René Descartes (1596 - 1650), em seu livro Discurso do Método (1637), (DESCARTES, 1999, p. 62)

5 Refere-se aos hotéis situados na linha costeira do Estoril.

6 Segundo o site sobre a Descolonização do canal RTP, "acabaria por ser o termo "retornado" a ficar consagrado, nomeadamente através da criação do Instituto de Apoio ao Retorno de Nacionais, ou IARN (Decreto-Lei n¹69/75, de 31 de março de 1975)"(LIRA, 2018). Disponível em: <https://media.rtp.pt/descolonizacaoportuguesa/pecas/o-retorno/>. 
Apoio:

\section{NTí pkofop}

Programa de Pós-Graduação em Letras da

Universidade Federal Fluminense (GPL/UFF)

"Apoiado pela Universidade Federal Fluminense com recursos do Programa Auxílio Publicação - PROPPI, 2014"

Realização:

Núcleo de Estudos de Literatura Portuguesa e Africana da UFF (NEPA) 


\section{COLABORADORES}

Silvio Renato Jorge

Margarida Calafate Ribeiro

Fátima da Cruz Rodrigues

Paulo de Medeiros

Kathrin Sartingen

Sophie Baltas

Felipe Cammaert

Daniel M. Laks

Roberta Guimarães Franco

Sheila Khan

Nicola Biasio

Rafaella Cristina Alves Teotônio

Larissa Fonseca e Silva

Eliana da Conceição Tolentino

Rodrigo Cavelagna

Claudia Amorim

Suzana Costa da Silva

ISSN 1984-2090

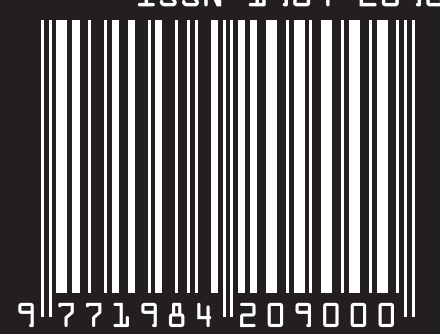

